\title{
ADOLESCÊNCIA E O TRAUMÁTICO: SOBRE ABUSO SEXUAL E AS VICISSITUDES DO SUJEITO
}

\author{
Adolescence and the Traumatic: On Sexual Abuse and the Vicissitudes of the Subject
}

Adolescencia y el Traumático: Sobre Abuso Sexual y las Vicissitudes del Sujeto

L'adolescence et le Traumatisme : Sur l'Abus Sexuel et les Vicissitudes du Sujet

DOI: $10.5020 / 23590777 . r s . v 17 i 3.6955$

\author{
Roberta Araujo Silva (Lattes) \\ Psicóloga. Mestra em Psicologia.. \\ Leônia Cavalcante Teixeira (Lattes) \\ Profa. Titular do Programa de Pós-Graduação em Psicologia da Universidade de Fortaleza.
}

\begin{abstract}
Resumo
O atendimento de Liz, uma adolescente de 14 anos de idade, abusada sexualmente, é o início de uma discussão acerca da investigação e do atendimento psicanalítico de adolescentes que vivenciaram situação de abuso sexual. Considera-se a vivência de abuso sexual como traumática, de acordo com as concepções teórico-clínicas de Freud, Ferenczi e Winnicott. Este ensaio teve como objetivo conhecer, por meio da escuta psicanalítica, as implicações subjetivas referentes à vivência de abuso sexual na adolescência. Para tal, foram utilizadas consultas terapêuticas no atendimento com a adolescente após sua experiência traumática de abuso. O trabalho de investigação do psiquismo é operado com suporte na constituição de um setting profissional adequado, em que é possível ao terapeuta o uso da experiência de mutualidade. Na sua clínica, Donald Winnicott desenvolveu a consulta terapêutica, um método de investigação e atendimento em Psicanálise, que possibilita uma exploração integral do primeiro atendimento, bem como enseja encontrar em determinados pacientes o seu conflito psíquico e intervir de modo a proporcionar saúde psíquica. Com o amparo no atendimento de Liz, discute-se a contribuição da Psicanálise para a compreensão do impacto do abuso sexual no psiquismo, sobretudo no aprofundamento do conhecimento sobre a singularidade dos destinos psíquicos dados à experiência traumática. Contextos distintos e múltiplas repercussões associam-se a cada vivência de abuso sexual, que deve ser analisada em sua complexidade. Em conclusão, o atendimento psicanalítico por meio das consultas terapêuticas é um importante instrumento de intervenção para os profissionais que atendem casos de violência em todos os âmbitos institucionais.
\end{abstract}

Palavras-chave: abuso sexual; adolescência; psicanálise; trauma; consulta terapêutica.

\section{Abstract}

It takes into consideration the different contexts and multiple repercussions associated with each specific experience of sexual abuse in adolescence. It is based on the premise that the psycho-dynamic approach offers the possibility to access the subjective implications of sexual abuse in adolescence. This paper used to illustrate the case study of Liz, a 14-years old girl interviewed after being sexually abused. The purpose of this paper is to discuss the contribution of the use of the Therapeutic Consultation to understand the impact of the sexual abuse of adolescents, especially the unique vicissitudes of being after the traumatic experience. Donald Winnicott developed this psychodynamic approach as a way to make the fullest use of the undefended material of the history-taking of the first interview or interviews. It requires an appropriate analytic setting, a holding environment, where the analyst can make use of the experience of mutuality. The objective of the Therapeutic Consultation is to identify the psychic conflict and to intervene to provide mental health. In conclusion, the psychoanalytic technique of Therapeutic Consultation is a useful mean of intervention for professionals who have to deal with cases of sexually abused adolescents in institutions. 
Keywords: sexual abuse; trauma; adolescent abuse; psychoanalysis; therapeutic consultation.

\section{Resumen}

La atención de Liz, una adolescente de 14 años de edad, abusada sexualmente, es el paso inicial para una discusión acerca de la investigación y la atención psicoanalítica de adolescentes que han vivido una situación de abuso sexual. Consideramos la vivencia de abuso sexual como traumática, de acuerdo con las concepciones teórico-clínicas de Freud, Ferenczi y Winnicott. El presente trabajo tuvo como objetivo conocer, por medio de la escucha psicoanalítica, las implicaciones subjetivas referentes a la vivencia de abuso sexual en la adolescencia. Para ello, se utilizaron consultas terapéuticas en la atención con la adolescente, después de su experiencia traumática de abuso. El trabajo de investigación del psiquismo se opera a partir de la constitución de un ajuste profesional adecuado, donde es posible al terapeuta el uso de la experiencia de mutualidad. Desde su clínica, Donald Winnicott desarrolló la consulta terapéutica, un método de investigación y atención en Psicoanálisis, que posibilita una exploración integral de la primera atención, así como encontrar en determinados pacientes su conflicto psíquico e intervenir para proporcionar salud psíquica. A partir de la atención de Liz, se discute la contribución del Psicoanálisis para la comprensión del impacto del abuso sexual en el psiquismo, sobre todo en la profundización del conocimiento sobre la singularidad de los destinos psíquicos posterior a la experiencia traumática. Diferentes contextos y múltiples repercusiones se asocian a cada vivencia de abuso sexual, que debe ser analizada en su complejidad. En conclusión, la atención psicoanalítica a través de las consultas terapéuticas es un importante instrumento de intervención para los profesionales que atienden casos de violencia en todos los ámbitos institucionales.

Palabras clave: abuso sexual; adolescencia; psicoanálisis; traumatismo; consulta terapéutica.

\section{Résumé}

L'assistance personnalisée de Liz, une adolescente de 14 ans, abusée sexuellement, c'est le départ pour un débat sur l'investigation et le soin psychanalytique des adolescents qui ont vécu situations d'abus sexuel. On considère l'expérience d'abus sexuel comme traumatique, conforme les conceptions théorique-clinique de Freud, Ferenczi et Winnicott. Cette recherche a eu le but de connaître, par l'écoute psychanalytique des implications subjectives relatives aux expériences d'abus sexuel à l'adolescence. Pour cela, on a utilisé visites thérapeutiques dans les assistances personnalisées avec l'adolescente, après leurs expériences traumatiques d'abus. Le travail de recherche de la psyché est basé sur la constitution d'un cadre professionnel approprié, où c'est possible le thérapeute utiliser l'expérience de la mutualité. À partir de sa clinique, Donald Winnicott a développé la consultation thérapeutique, une méthode d'investigation et d'assistance en psychanalyse, qui permet une exploration intégrale de la première assistance, ainsi que pour trouver dans certains patients leur conflit psychique et intervenir pour assurer la santé psychique. À partir de l'assistance de Liz, on débat la contribution de la psychanalyse pour la compréhension de l'impact de l'abus sexuel sur la psyché, en particulier dans l'approfondissement de la connaissance de l'unicité des destinées psychiques apportées à l'expérience traumatique. Des contextes différents et des répercussions multiples sont associés à chaque expérience d'abus sexuel, qui doit être analysée dans sa complexité. En conclusion, les soins psychanalytiques par des consultations thérapeutiques constituent un important outil d'intervention pour les professionnels qui traitent des cas de violence dans tous les milieux institutionnels.

Mots-clés: abus sexuels; l'adolescence; psychanalyse; traumatisme; assistance thérapeutique.

Este artigo é recorte de uma pesquisa de mestrado intitulada "O abuso sexual e o traumático: escuta de adolescentes numa perspectiva psicanalítica". É uma investigação de teor qualitativo, realizada por meio de estudo de casos clínicos. Aqui se reporta o atendimento de Liz, nome fictício dado a uma adolescente de 14 anos de idade, abusada sexualmente pelo padrasto dos seis aos treze anos, a qual realizou denúncia de violência de abuso sexual na Delegacia de Combate à Exploração de Crianças e Adolescentes (DCECA). $\mathrm{O}$ atendimento de Liz é o começo de uma discussão acerca da investigação do funcionamento psíquico e do atendimento psicanalítico de adolescentes que vivenciaram situação de abuso sexual, bem como da contribuição da Psicanálise para o entendimento do impacto operado pelo abuso sexual no psiquismo.

O abuso sexual é um fenômeno mundial, em curso na totalidade das classes sociais. Configura um problema social, subjetivo e cultural, vivenciado por crianças e adolescentes de maneiras diversas, das mais cruéis às mais sutis, desde os tempos primitivos, em variadas culturas (Minayo, 2001). É um tema bastante pesquisado nas últimas décadas, sob variadas perspectivas. Evidencia-se, entretanto, a carência de estudos que privilegiem o sujeito e sua história, considerando que a vivência de abuso sexual varia de acordo com a singularidade e a história de vida de cada um. 
Dentre as violências cometidas contra crianças e adolescentes, o abuso sexual se destaca por denotar características específicas e grande potencial de dano físico e psíquico, uma vez que incide diretamente sobre a saúde física e mental, podendo causar danos que persistirão por toda a vida. Com frequência, caracteriza-se como tipo intrafamiliar, contribuindo para a manutenção do sigilo em torno do ocorrido (Aded, Dalcin, Moraes \& Cavalcanti, 2006; Brauner \& Carlos, 2004; Habigzang, Koller, Azevedo \& Machado, 2005; Pfeiffer \& Salvagni, 2005).

A literatura especializada define o abuso sexual como todo e qualquer ato ou jogo sexual - relação heterossexual ou homossexual - com ou sem contato físico, com intenção de estimular sexualmente a criança ou o adolescente ou cujo objetivo é utilizá-lo para obter satisfação sexual de alguém que atingiu um estágio de desenvolvimento psicossexual mais adiantado; envolvendo, assim, uma pessoa que não compreende ou que ainda não adquiriu maturidade (Boarati, Sei \& Arruda, 2009; Brasil, 2006; Habigzang, Koller, Azevedo \& Machado, 2005; Minayo, 2001; Pfeiffer \& Salvagni, 2005; Santos \& Dell'Aglio, 2010).

O fenômeno do abuso sexual contra crianças e adolescentes implica uma compreensão do processo que seu caráter sexual confere, como: transforma as relações afetivas entre adultos e crianças ou adolescentes em relações erotizadas e genitalizadas, negando os limites intergeracionais; descaracteriza as representações sociais e funções dos adultos - de pai a agressor, por exemplo; confunde as relações entre os adultos e as crianças ou adolescentes definidas socialmente, tornandoas dominadoras, agressivas e arriscadas, em lugar de democráticas, afetivas e protetoras (Faleiros, 2000). Em toda situação de abuso sexual, há exercício de poder do agressor sobre a vítima (Gabel, 1997), vista como um objeto, destituída de direitos e sentimentos (Amazarray \& Koller, 1998).

Vivenciar uma experiência de abuso sexual é inscrever uma violência no corpo e, principalmente, no psiquismo, pois incide diretamente na manutenção do funcionamento psíquico. É um tipo de violência diferenciada que implica um sentimento de enorme solidão e confusão, em que a criança foi utilizada com a finalidade de satisfazer sexualmente o adulto e experimentou sensações sexuais antes desconhecidas. Mesmo numa situação de passividade física, a criança ou adolescente participa psiquicamente, pois sensações são despertadas, mas não integradas; desejos, afetos e fantasias entram em ação, facilitando ou dificultando a sedução (Fuks, 1998, 2006) e a elaboração psíquica.

Considerando a complexidade das questões envolvidas nas situações relacionadas ao abuso sexual, neste trabalho, buscouse compreender as implicações subjetivas referentes à vivência de abuso sexual na adolescência, utiliza-se a Psicanálise como referencial teórico e técnico, enfocando a noção de trauma psíquico como desdobramento da referida vivência.

\section{O Abuso Sexual como Trauma Psíquico: Freud, Ferenczi e Winnicott}

Segundo Laplanche e Pontalis (2001), o trauma pode ser compreendido como um “(...) acontecimento da vida do sujeito que se define pela sua intensidade, pela incapacidade em que se encontra o sujeito de reagir a ele de forma adequada, pelo transtorno e pelos efeitos patogênicos duradouros que provoca na organização psíquica.” (P. 522). Conforme indicam os referidos autores, Freud atribui ao conceito de trauma uma ideia econômica. Assim, “(...) o traumatismo caracteriza-se por um afluxo de excitações que é excessivo em relação à tolerância do sujeito e à sua capacidade de dominar e de elaborar psiquicamente estas excitações." (Laplanche \& Pontalis, 2001, p. 522).

Sabe-se que Freud nunca sistematizou um conceito de trauma, embora essa ideia pontilhe em toda a sua obra. Ao longo de seus escritos, o trauma se mostra de modo distinto à medida que seus estudos em Psicanálise avançam. Após ocupar um papel de determinante na etiologia da neurose e ser deixado em segundo plano após a descoberta das fantasias, o trauma voltou à cena, ocupando lugar de destaque na teoria pulsional.

Em 1896, no primoroso texto “A etiologia da histeria”, Freud (1896, p. 210) aponta o efeito traumático da violação física e psíquica do abuso sexual no psiquismo infantil: “(...) todas essa [sic] incongruências grotescas, mas trágicas, mostram-se impressas no desenvolvimento posterior do indivíduo e de sua neurose, em incontáveis efeitos permanentes que merecem ser delineados nos mínimos detalhes."

Para Freud (1896/1996a), o caráter traumático e patogênico de uma recordação decorre do fato de não ter havido nenhuma reação, nem motora, tampouco verbal, ao acontecimento, ficando o afeto ligado à recordação e esta excluída da cadeia de representações, mas constituindo, juntamente com outras cenas traumáticas, as próprias cadeias associativas, ainda que não sejam lembradas. O trauma psíquico pode ser efeito de um só e intenso trauma, ou de várias experiências traumáticas, que se acumulam ao longo da vida, ou seja, pode advir do impacto de um acontecimento que poderá deixar marcas corporais, como no abuso sexual, mas ele não é provocado pela lesão em si, mas pelo susto, pela surpresa.

A situação traumática está intimamente relacionada à vivência de desamparo do ego ante um excesso de excitação pulsional, provocando angústia, cujo efeito é danoso à simbolização e elaboração do sujeito, formando sintomas. Considera- 
se a elaboração psíquica como capacidade do aparelho psíquico de dominar e integrar as excitações no psiquismo e estabelecer conexões associativas entre elas (Laplanche \& Pontalis, 2001). O evento traumático é registrado, impresso e inscrito, mas não é simbolizado, necessitando ser transposto do físico para o psíquico e, posteriormente, transcrito do registro do sensorial-perceptivo para o da representação-palavra (Uchitel, 2011).

Muito embora Freud (1896/1996a; 1920/1996b), inicialmente, tenha formulado a teoria do trauma enfocando a relação do adulto com a criança para explicar a etiologia da neurose, posteriormente, ele retomou à ideia de trauma relacionada ao pulsional, cabendo ao psicanalista húngaro Sándor Ferenczi reaver a noção de trauma, relacionando-o ao papel do adulto na constituição do psiquismo infantil.

Em seu texto "Confusão de línguas entre os adultos e a criança", Ferenczi (1933/1992a) aborda o trauma, enfatizando o impacto das experiências reais de abuso sexual da criança na sua organização psíquica, a relação entre a criança e seu agressor e a dificuldade para o restabelecimento da confiança nos adultos, o que incide diretamente na transferência na situação analítica. "Confusão de línguas" é uma expressão utilizada por Ferenczi para explicar uma das fontes do trauma: a confusão entre a linguagem da ternura (sexualidade infantil, ingênua) e a linguagem da paixão (sexualidade adulta, culposa). Ao assinalar que a linguagem da criança é a linguagem da ternura, Ferenczi enfatiza, sobretudo, a importância da qualidade do vínculo com os objetos para o desenvolvimento psíquico da criança.

Conceber a existência de uma sexualidade infantil não significa o estabelecimento de uma simetria com a sexualidade adulta. $\mathrm{O}$ encontro entre ambas pode ser traumático. A criança é sexualizada e estabelece relações amorosas e eróticas com os adultos, mas, com sua sexualidade pré-genital, opera na linguagem da ternura, a qual é lúdica, imaginativa e onipotente, o que permite o desenvolvimento da capacidade de desejar. É por meio dela que, no encontro com o mundo adulto, o psiquismo infantil se expande, cria mais sentidos para o viver. Se, no entanto, nesse encontro, a criança for tomada pelo adulto na linguagem da paixão, perde-se a diferença, ocorrendo uma violência que pode acarretar interrupções, desvios e impedimentos (Ferenczi, 1933/1992a).

O abuso sexual, modelo do trauma desestruturante no construto teórico de Ferenczi (1933/1992a), corresponde ao primeiro tempo do trauma. O segundo tempo refere-se ao desmentido por parte do adulto, em quem a criança confia e recorre, buscando amparo e sentido para essa vivência. Ao negar a realidade do ocorrido ou ser indiferente ao sofrimento da criança, o adulto age de modo a impossibilitar que ela atribua um sentido ao ocorrido e o que ela experimenta é o abandono e o desamparo em total solidão, perde o prazer de viver e volta a agressão contra si. A confiança que ela possuía em si mesma e no mundo é abalada. Sentindo-se desamparada e abandonada, a criança tem de se haver com a culpa transmitida pelo adulto atormentado. Além disso, ela não pode abrir mão do amor do agressor. Com efeito, a solução psíquica encontrada é a introjeção do agressor com o seu sentimento de culpa, originando uma clivagem da personalidade ou cisão, cujo objetivo é proteger-se.

Sobre os destinos psíquicos do trauma, Ferenczi (1932/1990; 1934/1992b; 1933/1992a) aponta a clivagem psíquica, com dois destinos possíveis: a identificação com o agressor e a progressão traumática ou prematuração. Na identificação com o agressor, a criança é muito frágil para protestar. Ainda que em pensamento, ante a força e autoridade do adulto, introjeta aquele que a ameaça e agride. Portanto, pacientes que experimentaram um trauma grave não conseguem reagir ao desprazer pela defesa ou pelo ódio, uma vez que uma parte de sua personalidade ficou fixada num momento em que não era possível reagir ao meio externo, mas somente era possível uma mudança interna (autoplástica), a identificação, dado que essa antecede a defesa, porque o ego ainda não dispõe de meios para se defender (Ferenczi, 1933/1992a).

Na prematuração ou progressão traumática, “(...) a criança que sofreu uma agressão sexual pode, de súbito, sob pressão da urgência traumática, manifestar todas as emoções de um adulto maduro, as faculdades potenciais para o casamento, a paternidade, a maternidade, faculdades virtualmente pré-formadas nela." (Ferenczi, 1933/1992a, p. 104). A prematuridade acarreta uma insensibilidade que compromete a capacidade de expressão dos afetos de amor e ódio, de ser afetado pelo outro, e resulta numa diminuição da potência para se colocar de modo pessoal.

Assim sendo, na concepção de Ferenczi, o traumático psíquico resulta não somente do evento traumático propriamente, mas também da maneira como os adultos reagem ao sofrimento da criança, com indiferença ou descrédito. Para ele, o aspecto traumático é fruto das dificuldades encontradas na relação entre a criança e a família, da (in)capacidade da família cuidar para que as excitações provenientes do meio externo ou interno não atuem de modo traumático. Quando os adultos não se adequam às necessidades infantis, traumatizam, e os efeitos desses traumas são a dependência e a desconfiança. Ferenczi (1933/1992a) considera a realidade externa como produtora de traumas psíquicos, embora não tenha negado a importância das fantasias sexuais e seu poder traumático.

Assim como Ferenczi, Winnicott, com suporte na sua prática clínica, enfatizou a dimensão relacional, tanto nos processos de desenvolvimento inicial como na experiência analítica, além de apontar o fator ambiental como preponderante na questão do trauma. O pediatra e psicanalista britânico concebe o trauma como consequência das falhas ambientais no desenvolvimento e, em especial, na relação mãe-bebê. Segundo ele, o trauma adquire um significado, dependendo do estágio de desenvolvimento emocional - dependência absoluta; dependência relativa; rumo à independência - em que a criança se encontra. 
A concepção de desenvolvimento emocional primitivo de Winnicott (1945/1982) privilegia o ambiente e sua influência sobre o indivíduo, especialmente na primeira infância. De acordo com ele, a mãe é o primeiro ambiente que se constitui para o bebê, sendo que, no início, ambos estão fundidos, não havendo diferenciação ambiente-indivíduo. O ambiente, contudo, não é unicamente responsável pela saúde emocional do bebê, mas pode ser facilitador ou danoso. Quando o ambiente é facilitador, favorece o crescimento do indivíduo, que já traz na sua constituição uma tendência inata ao desenvolvimento; quando é danoso, o ambiente falha, podendo desencadear uma instabilidade emocional e a doença, principalmente se no início da vida (Abram, 2000). A série complementar estabelecida por Freud é retomada por Winnicott, isto é, personalidade é igual à constituição mais vivências infantis mais situação atual, quando este último considera a relação entre o bebê e o seu ambiente.

No início da vida, a mãe, ou quem exerce a função materna, funciona como um escudo protetor entre a criança e o mundo - estímulos externos - evitando falhas no cuidado e fornecendo ao bebê uma proteção quanto à traumatização. Os cuidados maternos é que possibilitam o desenvolvimento da criança, pois, assim, ela poderá experimentar o movimento espontâneo e viver as sensações próprias desse período inicial da vida. A continuidade dos cuidados e da sustentação física e psíquica (holding) mantidos pela mãe suficientemente boa proporcionam ao bebê a experiência de amor, amparo e confiança no ambiente, uma vez que, nesse momento, a comunicação verbal ainda não prevalece e o bebê registra aspectos relacionados à forma e não ao conteúdo. A presença materna e a continuidade e repetição dos cuidados estabelecem um ritmo que possibilitam ao bebê o desenvolvimento da capacidade de confiar nos objetos. Quando essa experiência de continuidade é interrompida pela necessidade de reação do bebê, isso implica um colapso do setor da confiabilidade no meio ambiente, resultando num fracasso ou trauma, com implicações no estabelecimento da integração do ego e estrutura de personalidade.

$\mathrm{O}$ trauma é ocasionado por um fracasso relativo à dependência em um processo que poderia seguir naturalmente a linha do desenvolvimento caso encontrasse um ambiente facilitador. Diz Winnicott (1965/1994b), p. 113): "O trauma é aquilo que rompe a idealização de um objeto pelo ódio do indivíduo, reativo ao fracasso desse objeto em desempenhar sua função". Quando, no entanto, o ambiente primeiro se adapta para depois fracassar, o fracasso contribui para a aquisição da capacidade de acreditar.

Na dependência absoluta, de acordo com Winnicott (1960/1983a), chegam ao bebê coisas boas e más, totalmente fora do seu alcance. Ele está em condições somente de aproveitar ou sofrer as perturbações. Nesse momento, o que é bom ou mau não é uma projeção de fato, mas, paradoxalmente, é crucial ao desenvolvimento saudável da criança que tudo o que chega seja percebido como uma projeção, pois a onipotência e o princípio do prazer estão plenamente em ação e ainda não há uma diferenciação entre eu e não-eu. $\mathrm{O}$ bebê e os cuidados maternos formam uma unidade.

A distinção entre o eu e o não-eu depende da maturidade emocional e intelectual, das condições favoráveis ou não. Inicialmente, o bebê não se atém à dependência e se relaciona com objetos subjetivos. Depois, se desenvolvendo satisfatoriamente, reconhece os objetos fora de seu controle onipotente, ou seja, objetos objetivamente percebidos. Nessa mudança do relacionamento com os objetos é que será possível ao indivíduo fazer sentido dos aspectos agressivos e fusionálos aos aspectos eróticos. É também nesse momento do desenvolvimento que o indivíduo saudável organiza a fantasia e o senso de realidade (Winnicott, 1965/1994a).

Posteriormente, na fase da dependência relativa, a criança é capaz de perceber os cuidados maternos, assim como suas necessidades. Além disso, ela pode relacioná-los aos impulsos pessoais. Nesse estágio, já se estabeleceu a diferenciação eu e não-eu. Portanto, há um ego integrado e as falhas maternas adquirem outro status: agora são importantes no processo ilusão-desilusão ou apresentação da realidade, que é fundamental para a criatividade. A criatividade resulta da sobrevivência da mãe e do bebê ao ódio que o bebê sente da mãe. É com suporte nessa experiência de sobrevivência que a criança cria seu espaço, e a mãe aceita a criatividade do bebê, havendo uma separação. As falhas são necessárias para que haja diferenciação, individuação e amadurecimento psíquico da criança. Esse processo (ilusão-desilusão) é a base para o desenvolvimento da ambivalência (Winnicott, 1965/1994b).

No decorrer do amadurecimento, a adaptação da mãe às necessidades do bebê deve levar a um fracasso adaptativo gradual ou desilusão, desde a capacidade da mãe de perceber a capacidade do bebê para suportar as falhas ambientais. Assim sendo, a mãe proporciona ao bebê a ilusão da experiência de onipotência para depois fracassar, num processo que vai da onipotência, regido pelo princípio do prazer, à desilusão e apresentação do princípio de realidade. Desse modo, o meio ambiente facilitador pode ser entendido como holding, progredindo para o handling, ou manejo, sendo acrescido da apresentação de objeto (Winnicott, 1974[1963]/1994f).

Vale ressaltar que, nos primeiros momentos de vida, o bebê necessita da mãe no papel de ego auxiliar para seu eu ir tomando configuração. Esse papel de proteção e sustentação, contudo, não é exclusivo da mãe, pois a família também pode exercê-lo: “(...) a família fornece à criança que cresce uma proteção quanto ao trauma” (Winnicott, 1965/1994b, p. 102). Logo, do mesmo modo que a família pode proteger a criança, também pode perturbá-la, traumatizando-a.

Ainda sobre o trauma, diz Winnicott (1965/1994b, p. 114): “(...) o trauma é a destruição da pureza da experiência individual por uma demasiada intrusão súbita ou impredizível de fatos reais, e pela geração de ódio no indivíduo, ódio do 
objeto bom experienciado não como ódio, mas delirantemente, como sendo odiado". No texto "A experiência mãe-bebê de mutualidade", Winnicott (1969/1994e) oferece uma definição taxativa do trauma:

Um trauma é aquilo contra o qual o indivíduo não possui uma defesa organizada, de maneira que um estado de confusão sobrevém seguido talvez de uma reorganização de defesas, defesas de um tipo mais primitivo do que as que eram suficientemente boas antes da ocorrência do trauma [...] Em outras palavras, experienciaram trauma e suas personalidades têm de ser construídas em torno da reorganização de defesas que seguem os traumas, defesas que devem precisar reter aspectos primitivos, tais como a cisão da personalidade. (p. 201).

Para Winnicott (1969/1994e), os destinos psíquicos do traumático apresentam como possibilidades de defesa a cisão da personalidade, a interrupção da continuidade do self e a construção de um falso self. No início da vida, o trauma compromete a construção de um self verdadeiro, dado que o desenvolvimento do ego depende do ambiente. Quando o ambiente fracassa, há um congelamento dessa situação de fracasso, uma "interrupção da continuidade do self" e um sentimento de desamparo, criando um falso self como defesa.

As expressões "falso self" e "verdadeiro self" são empregadas por Winnicott (1994g) “(...) na descrição de uma organização defensiva na qual se dá uma assunção prematura das funções de amamentação da mãe" (p. 36), em que o bebê, concomitantemente, se adapta ao meio ambiente e protege o verdadeiro self, fonte de seus impulsos. Nos casos de falso self, clinicamente, há uma vivência de não sentir-se real. Em tais casos, o self verdadeiro está aprisionado, não funciona e sua vivência é limitada, mas a espontaneidade e o impulso real, ou seja, o viver criativo, provém do verdadeiro self.

No desenvolvimento emocional, são possíveis duas vias de evolução. A primeira, quando há uma adaptação suficientemente boa da mãe - leia-se ambiente facilitador - e, como resultado disso, o bebê inicia a crença na realidade externa, que o atende magicamente, propiciando-lhe uma área de ilusão e o controle onipotente. Então, será possível à criança renunciar sua onipotência, gradativamente, pois os acontecimentos externos estão adaptados a sua espontaneidade, propiciando o desenvolvimento de um self verdadeiro e o reconhecimento do ilusório, ou seja, brincar de imaginar e simbolizar. A segunda via ocorre quando não há uma adaptação suficientemente boa por parte do ambiente, e o bebê se submete e desenvolve um falso self submisso, que atende à exigência do ambiente que a criança parece aceitar de bom grado.

No que tange ao trabalho analítico, Winnicott (1965/1994a) refere que a situação traumática deve ser reatualizada pela regressão à dependência no setting analítico, sendo o último um representante do ambiente. Para isso, é necessário um setting confiável e seguro ao paciente. Assim, será possível descongelar a situação de fracasso e possibilitar um novo posicionamento do ego - de falso self para um verdadeiro self. Há, no processo analítico, um desfazer-se gradual do falso self, em que o terapeuta ocupa o lugar de cuidador e assume as funções defensivas do falso self, possibilitando a emergência do verdadeiro self. Nesse tipo de trabalho, com pacientes traumatizados, o setting é modificado em relação ao enquadre clássico da Psicanálise, para um mais flexível, no qual mais importante do que a interpretação é a vivência de experiências organizadoras e o terapeuta possibilita o desenvolvimento da confiança que fora abalada no trauma. Ressalta que, como disse o próprio Winnicott (1965/1994a), no texto “A importância do setting no encontro com a regressão na psicanálise", os princípios básicos da análise estabelecidos por Freud são seguidos e fundamentais ao trabalho analítico.

Assim, pode-se afirmar que o setting winnicottiano é o setting materno, que atende às necessidades do indivíduo, com modalidades de intervenção estabelecidas com base na demanda do paciente ou consulta terapêutica, abordagem utilizada nesta pesquisa, na qual os atendimentos podem ser realizados em poucas sessões ou numa somente. É diferente do setting analítico freudiano, que trabalha o desejo privilegiando a transferência paterna, condizente com a clínica da neurose, pois, na neurose, os conflitos são intrapsíquicos, dizem respeito aos impulsos do id que ameaçam o ego, mantendo, assim, uma relativa independência do ambiente.

Winnicott (1963/1983b) faz uma correlação entre a relação mãe-bebê e a relação analítica. Assim como a mãe que se identifica com o seu bebê para atender as suas necessidades, na clínica com pacientes regredidos, o analista deve ser capaz de identificar-se com o paciente. Tal aspecto remonta a Ferenczi, quando assinala que o analista deve ser capaz de desenvolver uma "benevolência materna" e que só a compreensão não é suficiente, mas faz-se necessária uma experiência. De acordo com o psicanalista inglês, o analista não pode falhar até que o paciente o fará falhar com a sua história pessoal, o que significa que a falha aqui adquire uma importância crucial, pois é a oportunidade de o paciente experimentar, no processo analítico, na transferência, a falha original, ambiental, fora do seu alcance onipotente naquela época. Agora, na situação analítica, a falha transformada em dependência pelo analista está sob o controle onipotente do paciente. 


\section{Breves Considerações sobre o Método}

Esta pesquisa foi de caráter qualitativo, na medida em que seu interesse foi conhecer, mediante a escuta clínica em Psicanálise, as implicações e possíveis efeitos psíquicos referentes ao abuso sexual. Para isso, reportou-se à consulta terapêutica ou entrevista psicoterapêutica (Winnicott, 1965/1994a; 1965/1994c; 1968/1994d; 1971/1984) como método nos atendimentos clínicos, uma modalidade singular de produção do saber que envolve a comunicação inconsciente e permite a articulação entre teoria e clínica. A consulta terapêutica apoia-se na ideia de que, quando um setting profissional é adequadamente ofertado, o paciente que está sofrendo apresentará sua aflição, e o mais importante é o que acontece, independente do que for (Winnicott, 1965/1994c). Assim sendo, essa estratégia comporta um aprofundamento ao explorar diferenças e similaridades da questão investigada.

A pesquisa refere-se a um estudo de caso constituído com esteio em duas consultas terapêuticas com a adolescente apresentada pelo nome fictício de Liz, de 14 anos de idade, abusada pelo padrasto dos seis aos treze anos. A adolescente foi convidada a participar da pesquisa desde a realização de denúncia de abuso sexual junto à Delegacia de Combate à Exploração de Crianças e Adolescentes (DCECA), localizada no município de Fortaleza.

A pesquisa aconteceu em dois momentos distintos: o primeiro sucedeu na delegacia, por meio de anúncio público, que constituiu em informar sobre a pesquisa e convidar as adolescentes a participar. Esse momento aconteceu quando da realização do atendimento psicológico naquele mesmo espaço. O segundo momento da pesquisa, as consultas terapêuticas, foi realizado no consultório particular de Psicologia.

As questões éticas envolvendo sujeitos adolescentes em situação de vulnerabilidade foram consideradas em profundidade, discutindo-se a pesquisa e os atendimentos com a adolescente e seu responsável. Esta investigação foi submetida à apreciação e aprovação do Comitê de Ética em Pesquisa da Universidade de Fortaleza com o título "Abuso sexual: considerações psicanalíticas", autorização CAAE: 35908614.0.0000.5052, número do Parecer n. 1.104.622, em 12 de junho de 2015, seguindo todos os princípios éticos e a orientação da Resolução no . 466/2012 do Conselho Nacional de Saúde/Ministério da Saúde e pela Resolução nº. 016/2000 do Conselho Federal de Psicologia.

Por ser uma pesquisa com sujeitos vulneráveis, houve o compromisso de se acompanhar e encaminhar para cuidados necessários quaisquer eventualidades que pudessem surgir nos sujeitos, advindos da pesquisa, ressaltando que a ética clínica norteou toda a estratégia da pesquisa.

\section{Liz: A Escuta do Singular por Meio das Consultas Terapêuticas}

Liz, 14 anos, realizou denúncia de abuso sexual na DCECA por intermédio de sua mãe, em março de 2015. A adolescente foi abusada pelo padrasto dos seis aos treze anos, quando ele saiu de casa. Na época das consultas, Liz residia com a mãe e o irmão materno, de quatro anos de idade, filho do padrasto, Bartolomeu (nome fictício). Os pais de Liz separaram-se quando ela era criança. Desde a separação dos pais, ela ficou com a mãe, que, posteriormente, casou-se com Bartolomeu. O pai reside próximo e também se casou novamente, mas não teve outros filhos.

Liz é ótima aluna, cursa o $1^{\circ}$. ano do Ensino Médio e é líder de sala. Durante as consultas terapêuticas, mostrou-se comprometida com os estudos e com o papel de líder que ora ocupa e diz gostar. Além de estudar, ela pratica artes marciais, assim como seu pai, e vai começar a participar de competições, atividade da qual fala com prazer e tensão.

Na primeira consulta terapêutica, convido Liz a falar sobre sua vida, sobre si.

Liz: "Não sei por onde começar, se por depois ou antes de eu nascer."

Digo que ela comece por onde quiser.

Liz: "Eu morava com minha avó, lá tinha muito bicho e eu era alérgica, quase morri por causa disso e ela preferiu ficar com os bichos do que comigo (pausa). Aí eu fui morar na casa da minha tia. Meus pais se separaram quando eu era pequena, eu lembro que eles viviam brigando. Depois minha mãe começou a namorar o Bartolomeu e foram morar juntos.”

Nas consultas terapêuticas com Liz, ela traz algumas questões, apresentando seu conflito naquele dado momento.

Sobre o abuso sexual, ela nos diz:

“A primeira vez eu não lembro, mas ele ficava passando a mão em mim (chora). A primeira vez eu acordei com ele na minha cama, eu não falei nada. Não sei como, eu dei um chute nele. (...) A minha mãe desconfiou, uma vez ela levantou à 
noite e ele estava sentado na minha cama”.

Em outro momento, fala:

“Acontecia todo dia, era quando minha mãe saía pra ir trabalhar. Eu queria era esquecer tudo isso".

A respeito da revelação do abuso, Liz refere:

"Eu cresci sem pai e não queria que o meu irmão também crescesse sem pai. Eu sei como é sofrido (chora). Eles eram casados e a nossa religião só permitia separação por traição. Depois nós mudamos de igreja e lá tem grupo sabe, e uma pessoa que coordena chegou pra mim e pra minha mãe e perguntou se estava acontecendo, como ela podia ajudar. Foi só quando eu falei. Eu tinha medo que meu pai soubesse e fizesse alguma coisa com ele ou culpasse minha mãe."

"Acho que falei numa briga com a minha mãe. Ela falou mal do meu pai e eu disse: e o teu marido que faz isso e isso. Ele ouviu. Eu ia pra casa de uma amiga sozinha e minha mãe mandou ele ir me deixar de bicicleta. Ele foi o caminho todo falando: eu ouvi o que você falou pra sua mãe. Só repetindo. Até que eu não aguentei mais e pulei da bicicleta e fui andando atrás."

Liz fala sobre sua relação com a mãe:

"Minha mãe fez a denúncia, eu nem sabia. Quando as coisas melhoraram lá em casa - eu achei que ia ficar tudo bem -, ela resolveu fazer e eu só soube depois. Eu queria era esquecer isso, aí ela voltou com isso. (...) Ela não fala as coisas. Falou com uma amiga, eu fiquei sabendo pelas conversas. A mãe fala para as pessoas, já eu guardo as coisas só comigo. Eu nunca falei pra ninguém. Eu tinha vergonha, achava que eu tinha culpa.”

"Eu não sei direito quando ela soube, mas foi ano passado e a denúncia foi em março. Eu nem queria, achava que já tinha passado. Agora, eu vou ter duas provas esta semana, as provas que eu perdi pra ir à delegacia, e não consigo estudar. Eu não consigo parar de pensar nisso. (...) Em tudo o que aconteceu. Eu não paro de pensar que ela disse que eu tinha que ir à delegacia naquele dia. A amiga dela disse que tinha falado com a delegada e a delegada tinha dito que, se eu não fosse, ela mandava a viatura me buscar. Quando eu fui, a delegada disse que não tinha problema, que eu poderia ter ido outro dia."

Sobre a relação com o pai:

"Sabe, às vezes, eu acho que mais difícil do que o que aconteceu comigo é não ter tido meu pai por perto (chora). Eu acho que se meu pai fosse mais presente, ele não teria feito aquilo comigo."

"Meu pai disse que, se eu quisesse, eu podia ir morar com ele, não tinha problema. Disse até que dava pra eu fazer um cursinho pra eu estudar pro ENEM, que eu ia ficar só estudando. Eu ia ter mais tempo pra estudar, porque lá em casa eu faço muita coisa. (...) Se eu for morar com ele, não vou poder mais vir aqui nem na delegacia. Eu ajudo a minha mãe com o meu irmão. (...) Eu indo morar com o meu pai, não vou poder ficar saindo e, mesmo se eu sair com a minha mãe, ele vai querer saber pra onde, vou ter que dar satisfação e ele não sabe de nada. Eu tenho medo do que ele possa fazer se souber. Meu pai é muito impulsivo e, agora ele tem arma, é da Polícia. Ele disse, se alguma coisa acontecer comigo, ele não tá nem aí pra esse concurso. Não sei se ele vai saber nem quando. Não sei se ele vai ficar com raiva de mim porque eu não falei, ou vai culpar a minha mãe."

Liz trouxe para os atendimentos a sua busca pelas funções parentais - pai e mãe; fala dos pais que não a protegeram dos abusos reiterados do padrasto; da ausência de pai e mãe; não fala de amor nem de seus sentimentos em relação às figuras parentais.

Os abusos podem ser compreendidos como uma falha na função parental, que não protegeu a criança do que é excessivo, seja das tensões internas, seja das situações externas, como no caso do abuso sexual. Na concepção winnicottiana, o trauma é o resultado da não adaptação do ambiente às necessidades da criança; uma falha ambiental que acarreta reação da criança à intrusão. Reagindo à intrusão, a criança adapta-se ao ambiente, sendo invadida pelos estímulos externos e suas consequências nocivas, sobretudo quando elas se dão de modo repetitivo, formando um núcleo de reações patogênicas. Uma vez que o ambiente/família não se adaptou às necessidades da criança, ocorre um desenvolvimento prematuro do ego, acarretando dificuldades de separação e individuação, além de um investimento precoce na realidade externa e interna. 
Na situação de abuso sexual, a criança reage às agressões, submetendo-se e adaptando-se ao ambiente abusivo, numa reação autoplástica (modificação interna) ou numa saída para o falso self, alguns dos destinos do trauma na situação de abuso. Assim sendo, pode-se hipotetizar a ideia de que o abuso sexual pode vir a repousar sobre o que se relaciona à comunicação estabelecida entre a mãe e o bebê, sobre as falhas do ambiente-mãe na adaptação às necessidades do bebê. Como disse Winnicott (1971/1975), o bebê se vê no rosto da mãe, porém, quando isso não acontece, o bebê vê o que é refletido pela mãe e, consequentemente, busca adaptar-se ao que lhe é imposto.

O esquecimento dos detalhes e as falhas na memória, consoante o relato de Liz, possivelmente, são desdobramentos do evento traumático. Aos seis anos, idade que se iniciaram os abusos, possivelmente Liz ainda estava às voltas com as fantasias edipianas incestuosas. Nesse momento do desenvolvimento psicossexual, a situação de abuso pode ser sentida pela menina como tendo sido provocada por ela. Fantasia e realidade se confundem, emergindo daí o sentimento de culpa. Uma vez identificada com o agressor, a criança introjeta o sentimento de culpa do adulto; e o que antes era uma brincadeira terna, passa a ser um ato proibido que merece uma punição (Ferenczi, 1933/1992a). Tomada pelo sentimento de culpa, a criança vive a angústia: ser vítima ou não ser vítima?

Nas consultas terapêuticas, Liz fala sobre o início de sua vida, do abuso vivido e, principalmente, de sua relação com o casal parental. Ela comunica as falhas ambientais a que fora submetida; fala do pouco investimento amoroso da avó e dos pais; do descrédito e indiferença de sua mãe em relação ao ocorrido; e do distanciamento afetivo do pai. Entende-se que se, na situação de abuso, a excitação excessiva, a violência psíquica e física, e a impossibilidade de reagir - pelo ataque ou por uma fuga - dão lugar, inicialmente, a um estado traumático, é na relação com a mãe que o trauma encontra razões para se perpetuar no caso de Liz, por meio do desmentido.

Como ensina Ferenczi (1931/1992c), o mais danoso é o desmentido por parte do adulto, a quem a criança está ligada e que se apresenta como modelo identificatório para ela. A negação de que há um sofrimento. $\mathrm{O}$ adulto, ao negar a realidade do evento ou se mostrar indiferente ao sofrimento da criança, impossibilita a atribuição de um sentido ao ocorrido. $O$ resultado disso é a vivência do desamparo, abandono, solidão, e um estado de confusão por parte da criança. Isto pode ser visto quando Liz traz sua angústia ante a decisão que, solitariamente, tem que tomar: o convite para ir morar com o pai. Supõe-se que ela quer isso: ser protegida pelo pai, que ela vê como poderoso.

Cabe salientar que, para a Psicanálise, o pai é o instaurador da lei, interditor do incesto. Ir morar com o pai, no entanto, significa abandonar a mãe e o irmão; deixar o irmão aos cuidados da mãe, ou deixá-lo ser negligenciado pela mãe, como pode ela ter se sentido. Durante a consulta, ela comunica o seu estado de desamparo, solidão e desconfiança. Com isso, busca-se desempenhar papel ativo, colocando-se na posição de atender às necessidades dela: de ser cuidada por um adulto e, assim, estabelecer com ela possíveis opções ao lhe dizer pode pensar sobre o convite do pai e responder depois; que ela pode buscar esclarecimentos, no que se refere à denúncia, junto à Psicóloga na delegacia.

Ao final, Liz reaproximou-se do pai. Acredita-se que numa tentativa de ser protegida e cuidada, concedendo a esperança de um reposicionamento na sua posição subjetiva.

\section{Considerações Finais}

Conclui-se que, além da cena de abuso sexual, há uma história de vida em um contexto familiar específico, denotando marcas psíquicas que antecedem a vivência do abuso, já que as primeiras relações objetais e o investimento libidinal dispensado pela mãe-ambiente são essenciais para a criança construir sua identidade subjetiva e estabelecer relações objetais para o longo da vida.

Os abusos podem ser compreendidos como uma falha na função parental, que não protegeu a criança dos excessos, seja das tensões internas, seja das situações externas, como no caso da violência sexual. Desse modo, o atendimento clínico psicanalítico, por via do processo transferencial, possibilita ao sujeito uma retomada do seu desenvolvimento emocional sem a necessidade das defesas patológicas.

Com amparo no estudo de caso relatado, entende-se que a Psicanálise contribui para o entendimento dos processos mentais relativos ao funcionamento psíquico, sobretudo no aprofundamento do conhecimento sobre a singularidade dos destinos psíquicos dados a vivência traumática, bem como pela valorização e aposta na elaboração psíquica do trauma.

Verificou-se, nas consultas terapêuticas realizadas com a adolescente, que a clínica do trauma ou do abuso sexual está situada no campo da delicadeza, exigindo do terapeuta uma disponibilidade afetiva, num exercício de afetação mútua e sensibilidade clínica de saber o que, quando e como se deve comunicar algo, e que a comunicação é mais abrangente do que o conteúdo das falas. Na escuta de adolescentes abusadas sexualmente, é necessário abster-se de qualquer furor - normativo e/ou curativo - para estar com a pessoa em sua singularidade.

Por fim, distintos contextos e múltiplas repercussões são associados a cada vivência de abuso sexual, que deve ser 
analisada em sua complexidade. Ademais, o atendimento psicanalítico por meio das consultas terapêuticas é um importante instrumento de intervenção para os profissionais que atendem casos de violência em todos os âmbitos institucionais.

\section{Referências}

Abram, J. (2000). A linguagem de Winnicott: Dicionário das palavras e expressões utilizadas por Donald W. Winnicott (M. D. G. da Silva, Trad.). Rio de Janeiro: Revinter.

Aded, N. L. O., Dalcin, B. L. G. S., Moraes, T. M., \& Cavalcanti, M. T. (2006). Abuso sexual em crianças e adolescentes: Revisão de 100 anos de literatura. Revista de Psiquiatria Clínica, 33(4), 204-213.

Amazarray, M. R., \& Koller, S. H. (1998). Alguns aspectos observados no desenvolvimento de crianças vítimas de abuso sexual. Psicologia Reflexão e Crítica, 11(3), 559-578.

Boarati, M. C. B., Sei, M. B., \& Arruda, S. L. S. (2009). Abuso sexual na infância: A vivência em um ambulatório de psicoterapia de crianças. Revista Brasileira de Crescimento e Desenvolvimento Humano. 19(3), 426-434.

Brasil. Ministério da Saúde. (2006). Violência faz mal à saúde (Série B. Textos Básicos de Saúde). Link

Brasil. Conselho Nacional de Saúde. (2012). Resolução $n^{o} .466$ [Diretrizes e normas regulamentadoras sobre pesquisa envolvendo seres humanos]. Link

Brauner, M. C. C., \& Carlos, P. P. de. (2004). A violência intrafamiliar sob a perspectiva dos Direitos Humanos. In G. Maluschke, J. S. N. F. Bucher-Maluschke \& K. Hermanns (Org.), Direitos humanos e violência: Desafios da ciência e da prática. Fortaleza: Fundação Konrad Adenauer.

Conselho Federal de Psicologia. (2000). Resolução nº. 016. Link

Faleiros, E. T. S. (2000). Repensando os conceitos de violência, abuso e exploração sexual de crianças e de adolescentes. Espirito Santo: CECRIA.

Ferenczi, S. (1990). Diário Clínico. (A. Cabral, trad.). São Paulo: Martins Fontes. (Trabalho original publicado em $1969[1932])$

Ferenczi, S. (1992a). Confusão de línguas entre os adultos e a criança: a linguagem da ternura e da paixão. In Obras completas: Psicanálise IV. (A. Cabral, trad., pp. 97-106). São Paulo: Martins Fontes. (Trabalho original publicado em 1933)

Ferenczi, S. (1992b). Reflexões sobre o trauma. In Obras completas (A. Cabral, trad., Vol. 4, pp. 109-117). São Paulo: Martins Fontes. (Trabalho original publicado em 1934[1931-1932])

Freud, S. (1996a). A etiologia da histeria. In Edição standard brasileira das obras psicológicas completas de Sigmund Freud (J. Strachey, trad., Vol. 3, pp.187-215). Rio de Janeiro: Imago. (Trabalho original publicado em 1896)

Freud, S. (1996b). Além do princípio do prazer. In Edição standard brasileira das obras psicológicas completas de Sigmund Freud (J. Strachey, trad., Vol. 18, pp.11-75). Rio de Janeiro: Imago. (Trabalho original publicado em 1920)

Fuks, L. B. (1998). Abuso sexual de crianças na família: Reflexões psicanalíticas. Revista Percurso, 20, 120-126.

Fuks, L. B. (2006). Consequências do abuso sexual infantil. Revista Percurso, 18(36), 41-52.Gabel, M. (1997). Crianças vitimas de abuso sexual. (S. Goldfeder, Trad.). São Paulo: Summus.

Habigzang, L. F., Koller, S. H., Azevedo, G. A., \& Machado, P. X. (2005). Abuso sexual infantil e dinâmica familiar: Aspectos observados em processos jurídicos. Psicologia: Teoria e Pesquisa, 21(3), 341-348. 
Laplanche, J., \& Pontalis, J-B. L. (2001). Vocabulário de Psicanálise. (4a ed., P. Tamen, trad.) São Paulo: Martins Fontes.

Minayo, M. C. de S. (2001). Violência contra crianças e adolescentes: Questão social, questão de saúde. Revista Brasileira de Saúde Materno Infantil, 1(2), 91-102.

Pfeiffer, L., \& Salvagni, E. P. (2005). Visão atual do abuso sexual na infância e adolescência. Jornal de Pediatria, 5(81), 197-204.

Santos, S. S., \& Dell'Aglio, D. D. (2010). Quando o silêncio é rompido: O processo de revelação e notificação de abuso sexual infantil. Psicologia \& Sociedade, 22(2), 328-335.

Uchitel, M. (2011). Neurose traumática: Uma revisão crítica do conceito de trauma. (Coleção clínica psicanalítica, 3a ed.) São Paulo: Casa do Psicólogo.

Winnicott, D. W. (1982). Desenvolvimento emocional primitivo. In D. W. Winnicott, Textos selecionados: Da Pediatria à Psicanálise. (2a ed., J. Russo, trad., pp. 269-286). Rio de Janeiro: F. Alves. (Obra originalmente publicada em 1945)

Winnicott, D. W. (1983a). Teoria do relacionamento paterno-infantil. In D. W. Winnicott, O ambiente e os processos de maturação: Estudos sobre a Teoria do Desenvolvimento Emocional. (I. C. S. Ortiz, Trad., pp. 38-54). Porto Alegre: Artmed. (Obra originalmente publicada em 1960)

Winnicott, D. W. (1983b). Dependência no cuidado do lactente, no cuidado da criança e na situação analítica. In D. W. Winnicott, O ambiente e os processos de maturação: estudos sobre a Teoria do Desenvolvimento Emocional. (I. C. S. Ortiz, Trad., pp. 225-233). Porto Alegre: Artmed. (Obra originalmente publicada em 1963)

Winnicott, D. W. (1984). Consultas terapêuticas em psiquiatria infantil. (J. M. X. Cunha, trad., Série Analytica). Rio de Janeiro: Imago Ed. (Obra original publicada em 1971)

Winnicott, D. W. (1994a). A importância do setting no encontro com a regressão na psicanálise. In C. W. Winnicott, R. Sherpherd \& M. Davis (Orgs.), Explorações psicanalíticas: D. W. Winnicott. (J. O. de S. Abreu, Trad., pp. 77-81). Porto Alegre: Artes Médicas. (Obra original publicada em 1965)

Winnicott, D. W. (1994b). O conceito de trauma em relação ao desenvolvimento do indivíduo dentro da família. In C. W. Winnicott, R. Sherpherd \& M. Davis (Orgs.), Explorações psicanalíticas: D. W. Winnicott. (J. O. de S. Abreu, Trad. pp. 102-115). Porto Alegre: Artes Médicas. (Obra original publicada em 1965)

Winnicott, D. W. (1994c). O valor da consulta terapêutica. In C. W. Winnicott, R. Sherpherd \& M. Davis (Orgs.), Explorações psicanalíticas: D. W. Winnicott. (J. O. de S. Abreu, Trad., pp. 244-248). Porto Alegre: Artes Médicas. (Obra original publicada em 1965)

Winnicott, D. W. (1994d). O jogo do rabisco. In C. W. Winnicott, R. Sherpherd \& M. Davis (Orgs.), Explorações psicanalíticas: D. W. Winnicott. (J. O. de S. Abreu, Trad., pp. 230-243). Porto Alegre: Artes Médicas. (Obra original publicada em 1968)

Winnicott, D. W. (1994e). A experiência mãe-bebê de mutualidade. In C. W. Winnicott, R. Sherpherd \& M. Davis (Orgs.), Explorações psicanalíticas: D. W. Winnicott. (J. O. de S. Abreu, Trad., pp. 106-202). Porto Alegre: Artes Médicas. (Obra original publicada em 1969)

Winnicott, D. W. (1994f). O medo do colapso (breakdown). In C. W. Winnicott, R. Sherpherd \& M. Davis (Orgs.), Explorações psicanalíticas: D. W. Winnicott. (J. O. de S. Abreu, Trad., pp. 70-76). Porto Alegre: Artes Médicas. (Obra original publicada em 1974[1963])

Winnicott, D. W. (1994g). Ideias e definições. In C. W. Winnicott, R. Sherpherd \& M. Davis (Orgs.), Explorações psicanalíticas: D. W. Winnicott. (J. O. de S. Abreu, Trad., pp. 36-37). Porto Alegre: Artes Médicas. 
Winnicott, D. W. (1975). O brincar e a realidade. (Coleção Psicologia Psicanalítica, J. O. de A. Abreu \& V. Nobre, Trad.). Rio de Janeiro: Imago editora Ltda. (Obra original publicada em 1971)

\section{Endereço para correspondência}

Roberta Araujo Silva

Email: robertamadeiro@gmail.com

Leônia Cavalcante Teixeira

Email: leonia.ct@gmail.com 